\title{
Envirocat EPZ10: A Recyclable Solid Acid Catalyst for the Synthesis of Biginelli-type 3,4-Dihydropyrimidin-2(1H)-ones
}

\author{
Key-Young Lee and Kwang-Youn $\mathrm{Ko}^{*}$ \\ Department of Chemistrv, Ajou Chiversity Smon 4+3-749, Korea \\ Received Julv 16, 2004
}

Key Words : Dihydropyrimidines. Solid acid catalyst. Biginelli reaction, Envirocats

Recently, 3.4-dihydropyrimidin-2(1H)-ones (4, Scheme 1) and their sulfur analogs (DHPMs) have attracted considerable interest due to their pharnaceutical properties such as antitumoral, antiviral and antihypertensive activities. 'The original method for the synthesis of DHPMs reported by Biginelli in 1893. involves the $\mathrm{HCl}$-catalyzed condensation reaction of ethyl acetoacetate. aldehydes, and urea or thiourea in ethanol. ${ }^{2}$ One najor drawback of this so-called Biginelli reaction. however. is the low to moderate yield that is often encountered when substituted aromatic $(20-60 \%)$ or aliphatic aldehydes $(10 \%)$ is used. ${ }^{3}$ To circumvent this problem. a variety of new reagents has been introduced in the literature. Recent examples involve the use of $\mathrm{LiClO}_{4}{ }^{\text {ta }}$ Lewis acids such as ytterbium triflate, ${ }^{\text {th }}$ cupric chloride. ${ }^{\text {tc }}$ manganese(III) acetate. Ail bisntuth triflate, ${ }^{\text {te }}$ cerium(III) chloride ${ }^{\text {ff }}$ copper(II) triflate. ${ }^{\text {ag }}$ ferric chloride. ${ }^{\text {th }}$ nickel chloride, ${ }^{\text {th }} \mathrm{BF}_{3}$ etherate/copper(II) acetate. ${ }^{\text {ti }}$ zirconium(IV) chloride, ${ }^{4 i}$ and polymer-supported ytterbium(III) reagent ${ }^{\text {th }}$ as well as Bronsted acids such as $p$-toluenesulfonic acid, ${ }^{4]}$ silica sulfuric acid ${ }^{\text {ath }}$ and $\mathrm{KHSO}_{4}{ }^{\text {th }}$ Also, Montmorillonite KSF was claimed to act as solid acid catalyst in the Biginelli reaction. $^{\text {4o }}$

Due to the ever-mounting environmental concern in the fields of chemistry, it is advisable to easily recover and recycle catalysts, especially expensive or toxic metallic ones for the next use. ${ }^{5}$ In this respect few of the catalysts mentioned above meet this criterion of green chemistry. Therefore. there is still room for further search for recyclable catalysts that can convert a variety of aldehydes in high<smiles>[R]C=CC1CCCCC1C(=O)OCC</smiles>

"Corresponding Author. e-mail: kykogajou.ac.kr
Table 1. Envirocats-catalyzed Synthesis of DHPMs ${ }^{2}$

\begin{tabular}{|c|c|c|c|c|}
\hline Entry & Catalysts & Solvent & Time (h) & Yield $(\%)^{c}$ \\
\hline la & EPZIO ( $10 \mathrm{~mol} \%)$ & Toluene & 6 & 84 \\
\hline lb & & $\mathrm{CH}_{2} \mathrm{Cl}_{2}$ & 36 & 36 \\
\hline lc & & $\mathrm{EtOH}$ & 48 & 45 \\
\hline ld & & THF & 48 & 44 \\
\hline le & & $\mathrm{CH}_{3} \mathrm{CN}$ & 48 & 55 \\
\hline lif & & Solvent-free $e^{d}$ & 6 & 80 \\
\hline 2 & EPZG $(10 \mathrm{~mol} \%)$ & Toluene & 15 & 78 \\
\hline 3 & EPIC ( $10 \mathrm{~mol} \%)$ & Toluene & 20 & 75 \\
\hline
\end{tabular}

"Reaction temperature: refluxing temperature. Molar ratio of aldehyde : ethyl acetoacetate : urea $=1: 1: 1.5 .{ }^{b}$ Composition of the actife substance in Enrirocats EPZ10. EPZG and EPIC is 12.20. 22, 0 by weight. respectively. "Yield refers to the isolated vield. "Reaction temperature: $110^{\circ} \mathrm{C}$

yields under mild reaction conditions.

In this paper, we describe an one-pot method for the Biginelli reaction using Envirocat EPZ10 as a recyclable solid acid catalyst (Scheme 1) ${ }^{7}$ EPZlO. which is prepared by supporting $\mathrm{ZnCl}_{2}$ on clay. is known to contain predominantly strong Lewis acid sites as well as weak Bronsted acid sites. ${ }^{8}$ EPZ 10 has been used as a catalyst for Friedel-Crafts alkylation. aromatic bromination and benzylation. ${ }^{\text {? }}$

Initially we studied a model reaction employing benzaldelyde, ethyl acetoacetate and urea in the presence of three types of Envirocats. namely EPZ10 (clay-supported $\mathrm{ZnCl}_{2}$ ). EPZG (clay-supported $\mathrm{FeCl}_{3}$ ) and EPIC (claysupported polyphosphoric acid). as shown in Table 1. All Envirocats catalysts were activated via azeotropic drying with toluene to remove loosely bound water in clay support. ${ }^{7}$ In refluxing toluene, EPZ10 was found to be the most reactive among three catalysts, giving the product in $84 \%$ isolated yield within $6 \mathrm{~h}$. In contrast. the classical Biginelli condition (cat. $\mathrm{HCl}$ in EtOH. reflux. $18 \mathrm{~h}$ ) gave $80 \%$ yield. The solvent effect was studied in the case of EPZ10catalyzed reaction (Table 1). Clearly. toluene was a much better solvent than other solvents tested in terms of yields. Lower boiling solvent (dichloromethane), protic solvent $(\mathrm{EtOH})$ and Lewis basic solvents (THF. $\mathrm{CH}_{3} \mathrm{CN}$ ) retarded the reaction. Also, the solvent-free reaction condition gave a 
Table 2. Envirocat EPZ10-catalyzed Synthesis of DHPMs ${ }^{a}$

\begin{tabular}{|c|c|c|c|c|c|}
\hline Entry & $R$ in 4 & $\begin{array}{l}\text { Time } \\
\text { (h) }\end{array}$ & $\begin{array}{l}\text { Yield } \\
(\%)^{s}\end{array}$ & $\underset{\left({ }^{\circ} \mathrm{C}\right)}{\operatorname{mp}}$ & $\operatorname{mp}_{\text {(lit.) }}\left({ }^{\circ} \mathrm{C}\right)$ \\
\hline 1 & $\mathrm{Ph}$ & 6 & 84 & $202-204$ & $200-202^{4 j}$ \\
\hline 2 & 2-fùryl & 6 & 83 & $201-203$ & $203-205^{4 j}$ \\
\hline 3 & $4-(\mathrm{OMe})-\mathrm{C}_{6} \mathrm{H}_{4}$ & 10 & 72 & $198-200$ & $199-20 \mathrm{I}^{\text {th }}$ \\
\hline 4 & $4-\left(\mathrm{NO}_{2}\right)-\mathrm{C}_{6} \mathrm{H}_{4}$ & 10 & 81 & $205-208$ & $206-208^{4 j}$ \\
\hline 5 & $3-\left(\mathrm{NO}_{2}\right)-\mathrm{C}_{6} \mathrm{H}_{4}$ & 8 & 83 & $225-227$ & $227-229^{4]}$ \\
\hline 6 & $2-\mathrm{ClC}_{6} \mathrm{H}_{4}$ & 6 & 88 & $214-215$ & $215-217^{4 m}$ \\
\hline 7 & $4-\mathrm{OHC}_{6} \mathrm{H}_{4}$ & 11 & 72 & $225-227$ & $227-228^{4 d}$ \\
\hline 8 & $\mathrm{PhCH}=\mathrm{CH}-$ & 12 & 56 & $230-232$ & $229-232^{4 j}$ \\
\hline 9 & $n$-pentyl & 10 & 68 & $158-160$ & $161-162^{43}$ \\
\hline 10 & n-hextl & 11 & 64 & $152-154$ & $152-154^{4]}$ \\
\hline 11 & isopropyl & 10 & 60 & $192-194$ & $194-195^{\text {th }}$ \\
\hline $12 \mathrm{a}^{\circ}$ & Ph & 12 & 80 & & \\
\hline $12 \mathrm{~b}^{7}$ & Ph & 24 & 42 & & \\
\hline $12 c^{e}$ & Ph & 6 & 78 & & \\
\hline $12 d^{f}$ & Ph & 12 & 75 & & \\
\hline
\end{tabular}

"Reaction conditions: 10 molo, catalyst, toluene, reflux. Molar ratio of aldehyde : ethyl acetoacetate : urea $=1: 1: 1.5{ }^{\text {b }}$ Yield refers to the isolated yield. 'The catalyst from the first nun (entry' 1 ) was dried in air at room temperature and used in the second run. ${ }^{d}$ The catalyst from the second run (entry 12a) was dried in air at room temperature and used in this third run. "The catalyst from the third run (entry 12b) was dried in air at $110^{\circ} \mathrm{C}$ for $3 \mathrm{~h}$ and used in this fourth run. Unactivated catalyst was used as received.

good yield of product (entry lf).

Further reactions of aromatic and aliphatic aldehydes were carried out using EPZ10 in refluxing toluene for convenience of following the reaction progress with TLC. The result of these reactions is summarized in Table 2 . Substituted or conjugated aromatic aldehydes and heteroaromatic aldehydes reacted readily within $6-12 \mathrm{~h}$. giving good yields of products (entries 2-8): aromatic aldehydes having either electronwithdrawing or electron-donating groups reacted in good yields. Also. aliphatic aldehydes reacted within $11 \mathrm{~h}$. providing $60-68 \%$ yield (entries $9-11$ ).

Next. the recyclability of EPZ10 was studied. The second run using the recovered catalyst that was dried in air at room temperature was slower as one can see by comparing the reaction times (entry 1 vs. 12a in Table 2). The third nun (entry 12b) employing the cataly'st from the second nun gave poor yield. despite longer reaction time. Fortunately. when the recovered catalyst that was dried in $110^{\circ} \mathrm{C}$ for $3 \mathrm{~h}$ was used. the original activity was restored (entry 12c). It is probable that the decrease in activity is due to the fact that two moles of water is generated for each mole of product and ever-increasing amount of water becomes absorbed in clay as the recycling of the catalyst is repeated. As an evidence. the cataly'st recovered from the first nun was similar in activity to the unactivated catalyst that is known to have loosely bound water (entry 12a vs. 12d), implying the detrimental effect of water on catalysis.

Recently: Kappe proposed that the first step of the Biginelli reaction the acid-catalyzed formation of acyl imine intermediate 5 formed by the reaction of the aldehyde

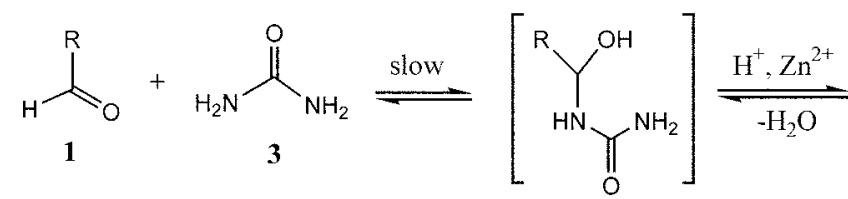<smiles>[R]/C=N\C([R17])N</smiles><smiles>CCOC1=[O+][Te]OC(C)=C1</smiles><smiles>[R]C(NC(N)=O)C(C(C)=O)C(=O)OCC</smiles>

5<smiles>[R]C1NC(=O)NC(C)=C1C(=O)OCCO</smiles>

with urea. is the rate-determining step. ${ }^{9}$ Further reaction of the iminium ion by acetoacetate gives an ureido 6 . which subsequently cyclizes to DHMPs 4 with expulsion of water. The catalytic effect of EPZ10 probably arises from the acidity of EPZ10 catalyzing the slow step as well as the activation of $\mathbf{5}$ with coordination with zinc metal. thus facilitating the addition of acetoacetate onto the more electrophilic iminium carbon center. ${ }^{\text {ta }}$

The following is a representative example: A solution of benzaldehyde ( $212 \mathrm{mg} .20 \mathrm{mmol})$. ethyl acetoacetate (260 mg. 2.0 nmol) and urea (180 mg. $3.0 \mathrm{mmol})$ in toluene (15 $\mathrm{mL}$ ) was treated with $\mathrm{EPZl} 10\left(225 \mathrm{mg}\right.$. $\mathrm{ZnCl}_{2}$ content $12 \%$. $10 \mathrm{~mol} \%$ ) under $\mathrm{N}_{2}$ atmosphere. The whole mixture was heated at refluxing temperature and the progress of the reaction was monitored by TLC. After $6 \mathrm{~h}$, the reaction mixture was concentrated in vacto and the residue was treated with hot $\mathrm{E} t \mathrm{OH}(30 \mathrm{~mL})$. The resulting suspension was filtered through a Büclner funnel and the filtrate was poured into cold water $(30 \mathrm{~mL})$. The resulting precipitate was collected and recrystallized in $\mathrm{EtOH}$, to give $435 \mathrm{mg}$ (84\%) of a white crystal, mp 202-204 ${ }^{\circ} \mathrm{C}$ (in lit. ${ }^{4 !} \mathrm{mp} 200-$ $\left.202^{\circ} \mathrm{C}\right)$.

In conclusion. we have found that Envirocat EPZ10 can serve as an environmentally friendly solid acid catalyst for the Biginelli reaction. $\mathrm{ZnCl}_{2}$, the active component of EPZ10 is non-toxic and cheap. The catalyst can be easily recovered by simple filtration and reused after activation by drying at $110^{\circ} \mathrm{C}$ in air.

\section{References and Notes}

1. Kappe. C. O. Ew J. 1fed Chem. 2000. $35,1043$.

2. Biginelli, P. Gazz. Chim. Ital 1893. 23, 360.

3. Folkers, K: Harwood. H. J.: Johnson, T. B. J. Am. Chem. Soc. 1932. $5+.3751$.

4. (a) Yadav. J. S.: Reddy. B. V. S.: Srinivas. R.: Venugopal. C.: Ramalingam. T. Smhesis 2001. 1341. (b) Ma. Y.: Qian. C.: Wang, L.; Yang, M. J. Org. Chem 2000, 65, 3864. (c) Gohain. M: Prajapati, D.: Sandhu. J. S. Symlet 2004, 235. (d) Kumar. K. A.; 
Kasthuraiah. M.: Reddy: C. S: Reddy C. D. Tetrahedron Lett. 2001. 42.7873. (e) Varala. R: Alam. M. M.: Adapa. S. R. Sintent 2003. 67. (f) Bose. D. S.: Fatima. L.: Merevala. H. B. J. Org. Chent 2003. 68. 587. (g) Paraskar. A. S.: Dewkar. G. K.: Sudalai. A. Tetrahedron Lett. 2003, 44, 3305. (1) Lu. I. Bai. Y. Smmesis 2002, 466. (i) Hu. E. H.: Sidler, D. R.: Dolling Ulf-H. J. Org. Chem. 1998, 63, 3454. (j) Reddy, C. V: Mahesh. M.: Raju. P. V. K.: Babu. T. R.: Reddy. V. V. N. Tefrahedron Lett. 2002. 13.2657. (k) Dondoni. A.: Massi. A. Tetrohedron Lett. 2001. t2. 7975. (1) Jin. T.: Zhang. S.: Li. T. Sinth. Conmun. 2002. 32. 1847. (m) Salehi. P.: Dabiri, M.: Zolfigol, M. A.; Fard, M. A. B. Tetrahedroft Lett. 2003. H. 2889. (11) Tu. S: Fang. F.: Zhu, S.: Li, T.: Zhang. X.: Zhulang. Q. Sylett 2004. 537. (o) Bigi. F. Carloni, S: Frullanti. B.: Maggi. R.: Sartori. G. Tetrohedron Leth. 1999. 40. 3465 .

5. Anastas. P. T.: Warner. J. C. Green Chentisty: Theory and Practice: Oxford Universitv: 1998.

6. For example. the recovery of $\mathrm{Yb}(\mathrm{OTf})_{3}$ from water seems cumbersome since water must by removed through heating and then drying under vacuum at $100^{\circ} \mathrm{C}$ for $2 \mathrm{~h}$. $^{\text {th }}$ In the case of polymer-derived $\mathrm{Yb}(\mathrm{III})$ resin. the activity of recycled resin is much lower than that of the original one. thus limiting the recyclability,

7. Envirocats catalysts are available from Contract Chemicals. England (wwwicontract-chemicals com).

8. Barlow: S. I.: Bastock. T. W.: Clark. J. H.: Cullent. S. R. Tetrahedron Lett. 1993.34. 3339

9. Kappe. C. O.J. Org. Chent 1997.62.7201.

10. It should be noted that the Biginelli reaction employing benzaldehyde in boiling toluene in the presence of $10 \mathrm{~mol}^{\circ} \cdot \mathrm{ZnCl}_{2}$ did not go to completion within $6 \mathrm{~h}$, giving poor vield $\left(-10^{\circ} \%\right)$ of product. This fact thus implies that clay plays an important role of enhancing catalytic activity of Lewis acid. probably by tying up water. On the other hand. the Biginelli reaction over Montmorillonite KSF (toluene. $100^{\circ} \mathrm{C}, 10 \mathrm{~h}$ ) is reported to give $35^{\circ}$ o vield of produet. ${ }^{\text {tn }}$ 